\title{
The Cellular Perspective on Mammary Gland Development: Stem/Progenitor Cells and Beyond*
}

\author{
M. S. Holland ${ }^{1}$ and R. E. Holland ${ }^{2}$ \\ ${ }^{1}$ Department of Veterinary Microbiology and Preventive Medicine, lowa State University, Ames 50011 \\ ${ }^{2}$ Department of Large Animal Clinical Sciences, University of Tennessee, Knoxville 37796
}

\begin{abstract}
Study of the mammary gland at the stem cell level is necessary for understanding mammary gland development. Knowledge of mammary gland development and growth is the first step toward formulating strategies to improve milk production. The success of these strategies requires an understanding of the dynamics of adult stem cells and their progeny in the development of the bovine mammary gland. The stem cell lineage pathway begins with adult stem cells and ends with the production of terminally differentiated cells. The progression of adult stem cells along the mammary gland stem cell lineage pathway requires the coordination of many events. One important event in this process is cell differentiation. This differentiation process evolves with a gradient appearance of cell organelles progressing from stem cells to terminally differentiated cells. To dissect differentiation, mechanisms that regulate stem cells to differentiate toward a particular cell fate must be identified. Ultrastructural characteristics assist in distinguishing cells in various stages of differentiation in the mammary gland cell lineage pathway. Cells in the lineage pathway can become either epithelial cells or myoepithelial cells. Epithelial cells function in the production and secretion of milk, whereas myoepithelial cells assist epithelial cells in milk secretion. This review focuses on current concepts regarding adult stem cells and the recent progress on bovine mammary gland stem/progenitor cell development and differentiation. Multistep strategies that incorporate manipulation of the mechanisms influencing lineage choices in the mammary gland will produce beneficial effects on mammary gland development and milk production.
\end{abstract}

(Key words: differentiation, gap junction, stem/progenitor cell)

Received August 12, 2004.

Accepted February 7, 2005.

Corresponding author: M. S. Holland; e-mail: hollandm@ iastate.edu.

*Presented at the ADSA/ASAS/PSA Joint Annual Meeting, July 2004, St. Louis, MO.
Abbreviation key: BMGPC = bovine mammary gland progenitor cell, $\mathbf{L D C}=$ large dark cell, $\mathbf{L L C}=$ large light cell, $\mathbf{S L C}=$ small light cell.

\section{INTRODUCTION}

Understanding the mechanism of milk synthesis and secretion depends on a conceptual understanding of mammary development. Full mammary epithelium development occurs during pregnancy and lactation (Topper and Freeman, 1980). The cycle of pregnancy-associated mammary gland proliferation, differentiation, and involution occurs many times during the lifespan of diary cattle (Turner and Huynh, 1991). Long-lived populations of stem cells, which have a near-infinite propensity to produce functional mammary gland cells, are responsible for this sequence of events. Mammary gland stem cells and their progeny control mammary gland growth and development through self-renewal. The story of tissue self-renewal and stem cells has been intertwined throughout history (LeBlond, 1964). The stem cell's unlimited self-renewal in vivo is simulated by the extensive expansion of stem cells seen in vitro.

Stem cell self-renewal is perpetuated through asymmetric and symmetric cell division. Cell division supplies a pool of daughter stem cells and progenitor cells capable of cell proliferation and subsequent differentiation that populate the mammary gland stem cell lineage pathway. The cells within this pathway provide the necessary components for mammary gland growth and development. The primary function of this pathway is to produce terminally differentiated functional mammary gland cells.

Insight into the mechanisms for stem/progenitor cell development lies with the differentiation process that occurs in the various stages of the lineage pathway. Strategies for enhancing milk production in cattle should be based on knowledge of the mechanisms by which lineage decisions are made during mammary gland growth and development. In this review, we highlight the recent advances on the characterization of bovine mammary gland stem/progenitor cells. Due to the limited studies on bovine mammary gland stem/ progenitor cells, some developments in mammary gland 
stem cell growth and differentiation in other mammalian species, specifically, rodent and human, will be included where appropriate. This review is not intended to be a comprehensive comparative mammary gland stem cell analysis.

\section{DEFINING STEM CELLS}

Stem cells are classified as totipotent, pluripotent, or multipotent based on the particular cell's behavior (DHHS, 2001). Totipotent means that the cell's potential is to form the entire organism. Pluripotent cells have the capability to form the inner cell mass that constitutes the 3 germ layers: mesoderm, endoderm, and ectoderm (Thomson et al., 1998). Pluripotent cells have an infinite life span and can produce daughter cells with more than one fate, and therefore have unlimited plasticity. This type of plasticity is observed during embryonic development and induced by different agents in the laboratory. Multipotent cells are specialized stem cells that are committed to giving rise to cells with a specific function (Weissman, 2000). These cells produce a lineage of daughter cells with a unidirectional terminal differentiation process. The molecular mechanisms responsible for converting a stem cell phenotype to a committed differentiated cell in unique lineage pathways are unknown. Although markers for differentiated cells are well documented in the literature, only a few markers for stem cells have been reported. Unfortunately, there are no known markers unique to all stem cells. Stem cells also are classified based on their origin as embryonic or adult stem cells. Two key features identify embryonic stem cells: 1) infinite or longterm self-renewal, and 2) plasticity.

The stem cell research community disagrees considerably regarding the properties that can be ascribed to stem cells (Weissman et al., 2001). Although reviewers demand that all cells classified as stem cells have unlimited plasticity, the plethora of stem cell types makes this limitation unreasonable (Lovell-Badge, 2001). The tissue of origin determines the characteristics of adult stem cells. The level of plasticity of adult stem cells depends on tissue of origin (Clarke, 2000; Anderson et al., 2001). At this point, there are no documented adult stem cells that are capable of forming all body cells.

Similar to mammary gland stem cells from other species, bovine mammary gland progenitor cells (BMGPC) have not been demonstrated to have plasticity comparable to that of pluripotent stem cells. Whereas the issue of plasticity is one that researchers have latched onto as a key identifying feature of stem cells in vitro, it is unclear whether plasticity is a normal event in vivo. Thus, plasticity may be a cell culture phenomenon unre- lated to any normal differentiation events occurring in the animal.

\section{Adult Mammary Gland Stem Cells}

Ideally, cell populations identified as adult stem cells should be capable of long-term self-renewal, generate genetically identical cells, and produce fully differentiated cells that have mature phenotypes capable of specialized functions appropriate for the tissue (Clarke et al., 2003). Initially, identifying adult stem cells involves demonstrating the appropriate cell morphology with distinct cellular architecture, renewal capacity linked to different stages of differentiation, and finally, by demonstrating that their progeny are truly functional (Smith and Medina, 1988; Chepko and Smith, 1997). Presumably, adult stem cells function to replace cells lost from normal cell death or damage. Upon exposure to the appropriate signals, stem cells respond by undergoing mitosis. Symmetrical mitosis will produce two new stem cells to expand the stem cell pool when necessary (Morrison et al., 1997). Once in the cell cycle, adult mammary gland stem cells appear quiescent and remain in the $G_{0}$ state for a prolonged period (Ellis and Capuco, 2002). Mammary gland adult stem cells are slow-cycling cells with the ability to respond to environmental cues and propagate additional stem cells or differentiate along a specific cell lineage. Once the stem cell commits to differentiation, it enters a brief period of rapid proliferation. Upon completing this stage, the stem cell cycles toward terminal differentiation to the specific cell lineage (Potten et al., 1979).

Asymmetrical cell division generates one daughter stem cell and one progenitor cell (Chepko and Smith, 1999). This process allows for the maintenance of a stem cell pool for future growth while simultaneously generating a differentiated cell population. Consequently, the stem cells are able to maintain their "stemness" in the midst of their differentiated progeny. By comparison, symmetrical cell division produces 2 daughter stem cells. This process enlarges the stem pool from one cell to many.

A single multipotent stem cell in mice can form the entire functional mammary gland (Kordon and Smith, 1998). However, the BMGPC have not yet been shown to fulfill transplantation criteria, which include integration into an in vivo mammary gland environment, survival, and production of functionally active cells of the mammary gland in vivo. Modified transplantation studies in the mouse have resulted in functional mammary outgrowths (Omerod and Rudland, 1986; Smith and Medina, 1988). However, repeated transplantations in multiple hosts resulted in a cessation of stem cell mitosis (Daniel et al., 1968). This result suggests the possi- 
ble isolation of progenitor cells rather than true stem cells that have the ability to divide asymmetrically.

A single bovine mammary gland stem cell can proliferate independently and form a colony of cells (Holland et al., 2003). However, although these colonies have a long self-renewal period, they do not expand infinitely in vitro. Growth senescence of BMGPC is seen after 44 serial passages. A similar outcome is seen with serial passages of epithelial outgrowths (Young et al., 1971). The senescence of cell growth appears related to the mitosis of the cells (Smith and Chepko, 2001). Cells with a higher frequency of mitotic activity enter senescence sooner than their counterparts with fewer mitotic events. Such results suggest the improbability that an adult multipotent stem cell can undergo multiple repeated cell divisions and maintain the features of a stem cell (Kordon and Smith, 1998). It is possible that multipotent stem cells enter the differentiation stage of the stem cell lineage pathway after exhaustion of ability to undergo cell division. Initially, the progenitor cells differentiate and are uncommitted to a specific cell lineage. However, a point of no return is entered once the progenitor cell commits to a particular cell lineage pathway.

\section{MAMMARY GLAND STEM CELL LINEAGE}

The mammary stem cell lineage pathway begins with the adult stem cell and ends with the functionally active terminally differentiated cell. In the pathway between these 2 cells are progenitor and intermediate cell types. The progenitor cells are in different stages of commitment to differentiation (Fuchs and Segre, 2000). Early progenitor cells are undifferentiated and uncommitted (Chepko and Smith, 1999; Ellis and Capuco, 2002; Holland et al., 2003). Thus, they have a degree of plasticity, although it probably is limited to cells that populate the mammary gland. At some point in the differentiation stage, the progenitor cells become intermediate cells and are committed to differentiating into epithelial cells or myoepithelial cells.

It is challenging to make a distinction between adult, tissue-specific stem cells and progenitor cells (Robey, 2000). The histological features of the mammary gland stem and progenitor cells are unique and assist in distinguishing the various populations within a given lineage (Chepko and Smith, 1997; Holland et al., 2003). Upon cell division, stem cells produce daughter stem cells with the same unlimited capability as the original stem cell. The other products are primary progenitor cells with a more limited potential. Both stem and primary progenitor cells are small light cells (SLC). The SLC have a blast-like appearance with a high nuclearto-cytoplasmic ratio (Holland et al., 2003). In a size comparison with their progeny, SLC are significantly smaller. The SLC have a junctional complex that includes adhering junctions or desmosomes (Ellis and Capuco, 2002). Desmosomes function in providing anchoring sites for cytoskeletal intermediate filaments in tissues that experience mechanical stress (Wheelock and Johnson, 2003). They are composed of cadherins, a family of adhesion molecules that maintain calcium-dependent cell coupling. The absence of calcium leads to disassociation of cells (Kartenbeck et al., 1991).

Another element of the cell junctional complex is tight junctions. Tight junctions occur between epithelial cells. Small light cells appear to have limited tight junctions when compared to their progeny (Chepko and Smith, 1997). While tight junctions are permeable or leaky during pregnancy, they become impermeable during lactation (Nguyen and Neville, 1998). During pregnancy, disorganization and a lack of interconnections within the tight junction network account for leakiness (Pitelka et al., 1973). At parturition, glucocorticoid secretion appears to regulate tight junction impermeability in the goat (Thompson, 1996). However, if milking frequency is decreased during lactation, tight junctions can again become leaky. Studies have shown that increased tight junction permeability associated with decreased milking frequency is transient (Stelwagen et al., 1992). Tight junctions reverse to the impermeable state when milking is increased. Decreased milking frequency is known to result in decreased milk yield (Hale et al., 2003). Tissue morphology suggests that the leakiness of the tight junctions negatively impacts milk yield through milk secretion (Stelwagen et al., 1992; Nguyen and Neville, 1998; Capuco et al., 2002). An increase in tight junction permeability was found with decreased milk secretion (Stelwagen et al., 1995). Thus, junctional complexes play a fundamental role in milk production at the cellular level. These results suggest that tight junctions have a role in mammary gland progenitor cells with a secretory function but less so in those without a secretory role such as SLC.

Morphologically, the cellular organelles that produce the cytoskeleton predominate in the SLC (Holland et al., 2003). Intermediate filaments, along with microtubules and microfilaments, comprise the organized, cytoplasmic networks commonly called the cytoskeleton. The cytoskeleton plays a role in differentiation of mammary gland cells (Zoubiane et al., 2004). Microtubules are undergoing constant assembly and disassembly (Mandelkow et al., 1991). Because one major function of adult stem cells is continuous self-renewal, it makes sense that these structures would be in abundance in cells undergoing cell division. Disruption of microtubules causes an arrested development in an early stage of the mammary gland stem lineage pathway (Nicker- 
son and Akers, 1983). The result is an inability to proceed to the end stage of terminal differentiation. The consequence of the disruption of microtubules is a decrease in milk production (Akers, 1985). Within SLC, microfilaments are abundant (Holland et al., 2003). Microfilaments connect to the plasma membrane and microtubules. Microfilaments control cell movement and shape change. The abundance of microfilaments provides a plausible explanation for the variability in cell shape observed in bovine SLC (Ellis and Capuco, 2002).

The primary progenitor cell is uncommitted and can divide along the epithelial or myoepithelial cell lineage (Chepko and Smith 1997; Holland et al., 2003). The primary progenitor cell can generate a secondary progenitor cell that is committed to either the epithelial or myoepithelial lineage. The secondary progenitor cell can undergo multiple divisions and generate intermediate progenitor cells. The intermediate progenitors may lengthen the self-renewal of stem cells by permitting the stem cells to depart the cell cycle and undergo a quiescent period (Chepko and Smith, 1999). The intermediate progenitor cells undergo gradual differentiation until they demonstrate terminal differentiation (Chepko and Smith, 1997; Holland et al., 2003). The gradual differentiation is marked by the appearance of cellular organelles associated with maturity or functionality. Although mitochondria are present in SLC, their numbers increase as the SLC passes through various stages of differentiation (Holland et al., 2003). Mitochondria are frequently seen closely associated with the tonofilament-desmosomal complex within differentiated mammary epithelial cells (Lee et al., 1979). As the cells progress toward terminal differentiation, they presumably require more energy for their secretory function, hence the cell's need for increased numbers of mitochondria to power the cell to produce and secrete milk. Other organelles appearing in differentiated mammary gland cells are perinuclear filaments, free ribosomes progressing to the appearance of glycogen, numerous rough endoplasmic reticula, free ribosomes, Golgi apparatus, and secretory granules (Holland et al., 2003).

Different stages in the mammary gland stem cell lineage pathway influence the uptake of cellular dyes. Stem and primary progenitor cells that occur in the early stage of the mammary gland cell lineage pathway have a limited ability to uptake cellular dyes (Ferguson, 1985; Smith and Medina, 1988; Ellis and Capuco, 2002; Holland et al., 2003). The term "light" in the SLC designation reflects this property. As these cells progress through the stem cell lineage pathway and differentiate, they gain the ability to take up cellular dyes.

\section{Distinguishing Features of Bovine Mammary Gland Stem/Progenitor Cells in Cell Culture}

Two overlapping classifications have been identified in the literature. Whereas adult mammary stem cells and their progenitors from human and mouse have been identified as type I and type II cells in cell culture experiments (Kang et al., 1997; Kao et al., 1997), research on cytology of rodent and bovine tissue sections designates the cells as small and large cells (Chepko and Smith, 1997; Ellis and Capuco, 2002; Chepko and Dickson, 2003). A combined designation has been used for BMGPC in vitro (Holland et al., 2003).

Examination of the mammary gland stem cell and progenitor cell at the light and ultrastructural level has revealed many similarities between mouse, human, and bovine cells. In addition, the cellular phenotypic features found in cell culture preparations correspond to those demonstrated in tissue sections. The type I cells consist of undifferentiated SLC and undifferentiated large light cells (LLC; Holland et al., 2003). These studies suggest that undifferentiated SLC contain both stem and primary progenitor cells (Chepko and Smith, 1997; Holland et al., 2003). The stem and primary progenitor cells are morphologically indistinguishable. Both are small, limited in uptake of cellular dyes, large nuclear to cytoplasmic ratio, and contain organelles indicative of undifferentiated cells. In contrast, Type II cells are large intermediate cells that include both differentiated large dark cells (LDC) and terminally differentiated cells. Histologic stains enter Type II cells and give them a dark staining pattern.

Type I cells grow in clusters surrounded by islands of type II cells (Kang et al., 1997; Holland et al., 2003). By comparison, large dark, large light, and small light cells grow in homogeneous pairs (Chepko and Smith, 1997; Ellis and Capuco, 2002). These results suggest that the cells are replicating by symmetrical division. Asymmetrical division is demonstrated in LDC, SLC, and LLC by the occurrence of mixed pairing containing one of each cell type. Likewise, the type I cells at the outer edge of the cluster and adjacent to type II cells are possibly displaying asymmetrical division (Kang et al., 1997; Holland et al., 2003). Type I and SLC both comprise a small percentage of the total cell population that corresponds with the percentage of stem cells in other organs. Type II, LDC, and LLC predominate in the total cell population.

Age of the animal appears to have a role in the distribution of cells in the mammary gland. The percentage of SLC declines in older animals, whereas the percentage of LLC and LDC increases (Ellis and Capuco, 2002). By comparison, a higher percentage of type I cells occurs in cultures at low passage levels and continually de- 
clines as passage level increases. At low passage levels, Type I and II cells are monomorphic but become pleiomorphic at high passage levels. Both SLC and LLC are pleiomorphic.

\section{DIFFERENTIATION OF MAMMARY GLAND STEM CELLS}

Differentiation of mammary stem cells is crucial for the development of the mammary gland. Terminally differentiated mammary gland cells were detected in cell culture (Holland et al., 2003). The majority of these cells progressed along the epithelial lineage pathway. The appearance of terminally differentiated cells, a subpopulation of Type II cells, coincided with providing the proper environment for inducing the bovine stem and progenitor cells to differentiate. In contrast, bovine mammary gland tissue sections had no terminally differentiated cells (Ellis and Capuco, 2002). This result would be expected because, prior to puberty, there is little mammary growth and development. This limited growth and development suggests that terminally differentiated cells are needed to function in milk production but are not required in significant numbers during gland development. Hence, one would expect to find the mammary gland populated by cells characterizing the early stem cell lineage, such as stem, progenitor, and intermediate cells, but not terminally differentiated cells.

The mechanism for the local control of mammary gland growth and differentiation has yet to be identified. Possible candidates include growth factors (Perusinghe et al., 1992), epithelial-stromal cell interactions (Atherton et al., 1992), cell-extracellular matrix interactions (Bissell and Barcellos-Hoff, 1987; Blum et al., 1987; Barcellos-Hoff et al., 1989), and direct cell-to-cell communication (Bruzzone et al., 1996). Two major types of differentiated cells within the mammary gland are epithelial and myoepithelial cells. The epithelial cells are the main secretory components during lactation (Capuco et al., 2003). Cessation of lactation is marked by a decrease in milk yield and loss of mammary epithelial cells. Maintaining this balance between epithelial secretory activity and loss of epithelial cells to normal turnover is dependent on long-term self-renewal and subsequent terminal differentiation to generate the necessary secretory epithelial cells. Whereas mammary gland stem cells demonstrate long-term self-renewal, their differentiated progeny are short-lived.

A rise in milk yield is attributed to an increase in secretory activity per cell but not to a simultaneous increase in the number of epithelial cells (Capuco et al., 2001). It is only following lactation with the normal turnover of epithelial cells that a shift in cell numbers is observed. The epithelial cells that are lost must be replaced before the next lactation cycle can successfully occur. Thus, differentiation of progenitor cells along the epithelial lineage occurs without simultaneous mitosis to increase the pool of stem and progenitor mammary gland cells. However, cell division to increase the epithelial cell numbers lost after lactation takes place late in the next pregnancy (Capuco et al., 1997). An inverse correlation exists between milk yield and cell numbers. As cell numbers increase, milk production decreases. Thus, asymmetric cell division occurs to replenish the stem/progenitor cell population. This event is followed by differentiation, and the resulting cell population consists of cells in different stages along the epithelial stem cell lineage.

\section{MAMMARY GLAND GROWTH AND MILK PRODUCTION}

The development of the mammary gland depends on the growth and differentiation of stem cells. Pregnancyassociated mammary gland growth differs from that witnessed in young animals (Wagner et al., 2002). Maximum milk production depends on the successful completion of the mammary gland stem cell pathway (Tucker, 1981; Knight and Wilde, 1987). Asymmetrical and symmetrical stem cell division provides the proliferative cell population needed. Cells in varying stages of differentiation in the lineage pathway are present to provide the increased secretory activity needed for lactation (Tucker, 1981). At the beginning of lactation, cells are rapidly proceeding through the differentiation process to provide the necessary cells to maintain mammary gland development and milk production. As lactation progresses, a corollary exists between the decline in mammary epithelial cell numbers and decrease in milk production (Capuco et al., 2001). The decrease in cell numbers is a consequence of apoptosis.

Following terminal differentiation and exhaustive secretion by cells, subsequent involution occurs. Involution begins with interference of cellular interactions allowing cell mobility and reorganization (Ossowski et al., 1979). Various events account for mammary gland growth and subsequent milk production.

\section{GAP JUNCTIONAL INTERCELLULAR COMMUNICATION}

Whereas the lack of specific cell markers in identifying stem cells has been viewed as a serious hindrance, the absence or presence of gap junction proteins is a feature that has been used to distinguish stem from differentiated cells (Kang et al., 1997; Holland et al., 2003). During development, the ability of cells to com- 
municate allows the transmission of certain signals necessary for regulatory control of cells and their neighbors (Lowenstein, 1979; Guthrie and Gilula, 1989; Warner, 1992). Gap junctions function to provide intercellular channels between adjacent cells that allow the passage of small molecules. Whereas the role of gap junctions in the mammary gland is unclear, they play a vital role in embryogenesis, cell differentiation, and coordination of tissue responses (Lowenstein, 1979; Guthrie and Gilula, 1989; Warner, 1992). In addition, gap junctions function in the control of cell proliferation (Bruzzone et al., 1996). The human breast expresses both Cx26 and Cx43 (Lee et al., 1991, 1992). The majority of cells populating the human breast are terminally differentiated cells. $\mathrm{Cx} 43$ is not expressed in adult stem cells from the human breast (Kao et al., 1995), kidney (Chang et al., 1987), cornea (Matic et al., 1997), brain (DowlingWarriner and Trosko, 2000), epidermis (Matic et al., 2002), pancreas (Tai et al., 2003), and bovine mammary gland (Holland et al., 2003). Although one could argue that adult stem cells may express other connexin proteins, it is highly unlikely. All adult stem cells examined thus far lack the characteristic intercellular communication that is the functional role for gap junctions. In contrast, differentiated cells of most organs express some type of gap junction and have functional gap junctional intercellular communication. Whereas differentiated bovine mammary epithelial cells had reduced $\mathrm{Cx} 43$ expression, there was a high level of gap junctional intercellular communication, possibly mediated by the compensatory connexin expression (Sia et al., 1999). A similar situation could be the case for stem cells.

The previously introduced theory of stem cells maintaining their "stemness" in the midst of their progeny is an interesting concept that may be explained by gap junctional intercellular communication. One consequence of intercellular communication is differentiation (Guthrie and Gilula, 1989; Warner, 1992). When potential mammary stem cells exit mitosis and enter a differentiated state, an increase in connexin expression and gap junctional intercellular communication occurs (Pozzi et al., 1995).

The production of gap junctions begins with the formation of connexin monomers in the endoplasmic reticulum, followed by oligomerization of connexons in the Golgi apparatus, and ending with their transport to the cell surface (Monaghan and Moss, 1996). The lack or limited number of endoplasmic reticula and Golgi apparatus in stem cells would not allow for the proper packaging and delivery to the cell surface of connexons and thus prevents gap junction formation.

In addition, the limited identification of cell surface markers in stem cells may be based on the distinct cytoplasmic undifferentiation. Adult stem cells do not contain the proper cellular machinery for the production of all the detectable cell surface markers seen in their differentiated progeny.

\section{CONCLUSION}

The study of bovine mammary gland stem/progenitor cells is still in its infancy. The development of culture conditions for long-term self-renewal and phenotypic stability is a critical step. The future progress toward selective proliferation and differentiation conditions for BMGPC will serve as a model of multicellularity. Studies on active genes in BMGPC will lead to a better understanding of mammary growth, development, and lactation.

\section{REFERENCES}

Akers, R. M. 1985. Lactogenic hormones: Binding sites, mammary growth, secretory cell differentiation and milk biosynthesis in ruminants. J. Dairy Sci. 68:501-519.

Anderson, D. J., F. H. Gage, and I. L. Weissman. 2001. Can stem cells cross lineage boundaries? Nature Med. 7:393-395.

Atherton, A. J., P. Monaghan, M. J. Warburton, and B. A. Gusterson. 1992. Immunocytochemical localization of the ectoenzyme aminopeptidase $\mathrm{N}$ in the human breast. J. Histochem. Cytochem. 40:705-710.

Barcellos-Hoff, M. H., J. Aggeler, T. G. Ram, and M. J. Bissell. 1989. Functional differentiation and alveolar morphogenesis of primary mammary cultures on reconstituted basement membrane. Development 105:223-235.

Bissell, M. J., and M. H. Barcellos-Hoff. 1987. The influence of Extracellular matrix on gene expression: Is structure the message? J. Cell Sci. 8:327-343.

Blum, J. L., M. E. Zeigler, and M. S. Wicha. 1987. Regulation of rat mammary gene expression by extracellular matrix components. Exp. Cell Res. 173:322-340.

Bruzzone, R., T. W. White, and D. L. Paul. 1996. Connections with connexins: The molecular basis of direct intercellular signaling. Eur. J. Biochem. 238:1-27.

Capuco, A. V., R. M. Akers, and J. J. Smith. 1997. Mammary growth in Holstein cows during the dry period: Quantification of nucleic acids and histology. J. Dairy Sci. 80:477-487.

Capuco, A. V., S. E. Ellis, S. A. Hale, E. Long, R. A. Erdman, X. Zhao, and M. J. Paape. 2003. Lactation persistency: Insights from mammary cell proliferation studies. J. Anim. Sci. 81:18-31.

Capuco, A. V., D. L. Wood, R. Baldwin, K. Mcleod, and M. J. Paape. 2001. Mammary cell number, proliferation, and apoptosis during a bovine lactation: Relation to milk production and effect of bST. J. Dairy Sci. 84:2177-2187.

Chang, C. C., J. E. Trosko, M. H. El-Fouhy, R. E. Gibson-D'Ambrosio, and S. M. D'Ambrosio. 1987. Contact insensitivity of a subpopulation of normal human fetal kidney epithelial cells and of human carcinoma cell lines. Cancer Res. 47:1634-1645.

Chepko, G., and R. B. Dickson. 2003. Ultratructure of the putative stem cell niche in the rat mammary epithelium. Tissue Cell 35:83-93.

Chepko, G., and G. H. Smith. 1997. Three division-competent, structurally distinct cell populations contribute to murine mammary epithelial renewal. Tissue Cell 29:239-253.

Chepko, G., and G. H. Smith. 1999. Mammary epithelial stem cells: Our current understanding. J. Mammary Gland Biol. Neoplasia 4:35-52.

Clarke, D. L. 2000. Generalized potential of adult neural stem cells. Science 288:1660-1663.

Clarke, R. B., E. Anderson, A. Howell, and C. S. Potten. 2003. Regulation of human breast epithelial stem cells. Cell Prolif. 36S:45-58. 
Daniel, D. W., K. B. DeOme, J. T. Young, P. B. Blair, and L. J. Faulkin. 1968. The in vivo life span of normal and preneoplastic mouse mammary glands: A serial transplantation study. Proc. Natl. Acad. Sci. USA 61:53-60.

DHHS. 2001. Stem cells: A primer. Dept. of Health and Human Services. Available: http://www.nih.gov/news/stemcell/primer.htm. Accessed March 17, 2005.

Dowling-Warriner, C. V., and J. E. Trosko. 2000. Induction of gap junctional intercellular communication, connexin 43 expression, and subsequent differentiation in human fetal neuronal cells by stimulation of the cyclic AMP pathway. Neuroscience 95:859-868.

Ellis, S., and A. V. Capuco. 2002. Cell proliferation in bovine mammary epithelium: Identification of the primary proliferative cell population. Tissue Cell 34:155-163.

Ferguson, D. J. 1985. Ultrastructural study of mitosis and cytokinesis in normal 'resting' human breast. Cell Tissue Res. 252:581-587.

Fuchs, E., and J. A. Segre. 2000. Stem cells: A new lease on life. Cell 100:143-155.

Guthrie, S., and N. Gilula. 1989. Gap junctional communication and development. Trends Neurosci. 12:12-16.

Hale, S. A., A. V. Capuco, and R. A. Erdman. 2003. Milk yield and mammary growth effects due to increased milking frequency during early lactation. J. Dairy Sci. 86:2061-2071.

Holland, M. S., M.-H. Tai, J. E. Trosko, L. D. Griffin, J. A. Stasko, N. C. Cheville, and R. E. Holland. 2003. Isolation and differentiation of bovine mammary gland progenitor cell populations. Am. J. Vet. Res. 64:396-403.

Kang, K. S., I. Morita, A. Cruz, Y. J. Jeon, J. E. Trosko, and C. C. Chang. 1997. Expression of estrogen receptors in a normal human breast epithelial cell type with luminal and stem cell characteristics and its neoplastically transformed cell lines. Carcinogenesis 18:251-257.

Kao, C.-Y., K. Nomata, C. S. Oakley, C. W. Welch, and C. C. Chang. 1995. Two types of normal human breast epithelial cells derived from reduction mammoplasty: Phenotypic characterization and response to SV40 transfection. Carcinogenesis 16:531-538.

Kao, C.-Y., C. S. Oakley, C. W. Welsch, and C.-C. Chang. 1997. Growth requirements and neoplastic transformation of two types of normal breast epithelial cells derived from reduction mammoplasty. In Vitro Cell Dev. Biol. 3:282-288.

Kartenbeck, J. 1991. Endocytosis of junctional cadherins in bovine kidney epithelial cells cultured in low $\mathrm{Ca}^{++}$ion medium. J. Cell Biol. 113:881-892.

Knight, C. H., and C. J. Wilde. 1987. Mammary growth during lactation: Implications for increasing milk yield. J. Dairy Sci. 70:1991-2000.

Kordon, E. C., and G. H. Smith. 1998. An entire functional mammary gland may comprise the progeny to form a single cell. Development 125:1921-1930.

Leblond, C. P. 1964. Classification of cell populations on the basis of their proliferative behavior. Natl. Cancer Inst. Monogr. 14:119-150.

Lee, C. S., G. Morgan, and F. B. Wooding. 1979. Mitochondria and mitochondria-tonofilament-desmosomal associations in the mammary gland secretory epithelium of lactating cows. J. Cell Sci. 38:125-135.

Lee, S. W., C. Tomasetto, D. Paul, K. Keyomarsi, and R. Sager. 1992. Transcriptional down-regulation of gap junction proteins blocks junctional communication in human mammary tumor cell lines. J. Cell Biol. 118:1213-1221.

Lee, S. W., C. Tomasetto, and R. Sager. 1991. Positive selection of candidate tumor suppressor genes by subtractive hybridization. Proc. Natl. Acad. Sci. USA 88:2825-2829.

Lovell-Badge, R. 2001. The future for stem cell research. Nature 414:88-91.

Lowenstein, W. R. 1979. Junctional intercellular communication and the control of growth. Biochim. Biophys. Acta 560:1-65.

Mandelkow, E. M., E. Mandelkow, and R. A. Milligan. 1991. Microtubule dynamics and microtubule caps: A time-resolved cryo-electron microscopy study. J. Cell Biol. 114:977-991.
Matic M., W. H. Evans, P. R. Brink, and M. Simon. 2002. Epidermal cells do not communicate through gap junctions. J. Invest. Dermatol. 118:110-116.

Matic M., I. N. Petrov, S. Chen, C. Wang, W. M. Dimitrijevch, and J. M. Wolosin. 1997. Stem cells of the corneal epithelium lack connexins and metabolite transfer capacity. Differentiation 61:251-260.

Monaghan, P., and D. Moss. 1996. Connexin expression and gap junctions in the mammary gland. Cell Biol. Int. 20:121-125.

Morrison, S. J., N. M Shah, and D. J. Anderson. 1997. Regulatory mechanism in stem cell biology. Cell 88:287-298.

Nickerson, S. C., and R. M Akers. 1983. Effect of prepartum blockade of microtubule formation on ultrastructural differentiation of the mammary epithelium in Holstein heifers. Int. J. Biochem. 15:717-775.

Nguyen, D.-A.D., and M. C. Neville. 1998. Tight junction regulation in the mammary gland. J. Mammary Gland Biol. Neoplasia $3: 233-246$.

Omerod, E. J., and P. S. Rudland. 1988. Mammary gland morphogenesis in vitro: Extracellular requirements for the formation of tubules in collagen gels by a cloned rat mammary epithelial cell line. In Vitro Cell. Dev. Biol. 24:17-27.

Ossowski, L., D. Biegel, and E. Reich. 1979. Mammary plasminogen activator: Correlation with involution, hormonal modulation, and comparison between normal and neoplastic tissue. Cell 16:929935.

Perusinghe, N. P., P. Monaghan, M. J. O’Hare, S. Ashley, and B. A. Gusterson. 1992. Effects of growth factors on proliferation on basal and luminal cells in human breast epithelial explants in serum-free culture. In Vitro Cell Dev. Biol. 28A:90-96.

Pitelka, D. R., S. T. Hamamoto, J. G. Duafala, and M. K. Nemanic. 1973. Cell contacts in the mouse mammary gland cells. J. Cell Biol. 56:797-818.

Potten, C. S., R. Schofield, and L. G. Lajtha. 1979. A comparison of cell replacement in bone marrow, testis, and three regions of surface epithelium. Biochim. Biophys. Acta 560:281-299.

Pozzi, A., B. Rizke, D. T. Kiang, N. B. Gilula, and N. M. Kumar. 1995. Analysis of multiple gap junction gene products in the rodent and human mammary gland. Exp. Cell Res. 220:212-219.

Robey, P. G. 2000. Stem cells near the century mark. J. Clin. Invest. 105:1489-1491.

Sia, M. A., T. L. Woodward, J. D. Turner, and D. W. Laird. Quiescent mammary epithelial cells have reduced connexin 43 but maintain a high level of gap junction intercellular communication. Dev. Gen. 24:111-122.

Smith, G. H., and G. Chepko. 2001. Mammary epithelial stem cells. Microsc. Res. Tech. 52:190-203.

Smith, G. H., and D. Medina. 1988. A morphologically distinct candidate for an epithelial stem cell in mouse mammary gland. J. Cell Sci. 90:173-183.

Stelwagen, K., V. C. Farr, S. R. Davis, and C. G. Prosser. 1995. EGTAinduced disruption of epithelial cell tight junctions in the lactating caprine mammary gland. Am. J. Physiol. 269:R848-R855.

Stelwagen, K., V. C. Farr, H. A. McFadden, C. G. Prosser, and S. R. Davis. 1997. Time course of milk accumulation-induced opening of mammary tight-junctions, and blood clearance of milk components. Am. J. Physiol. 273:R379-R386.

Stelwagen, K., D. G. Grieve, B. W. McBride, and J. D. Rehman. 1992. Growth and subsequent lactation in primigravid Holstein heifers after prepartum bovine somatotropin treatment. J. Dairy Sci. 75:463-471.

Tai, M. H., L. K. Olson, B. V. Madhukar, K. D. Linning, L. Van Camp, M. S. Tsao, and J. E. Trosko. 2003. Characterization of gap junctional intercellular communication in immortalized human pancreatic ductal epithelial cells with stem cell characteristics. Pancreas. 26:e18-26.

Thompson, G. E. 1996. Cortisol and regulations of tight junctions in the mammary gland of the late-pregnant goat. J. Dairy Res. 63:305-308.

Thomson, J. A., J. Itskovitz-Eldor, S. S., Shapiro, M.A. Waknitz, J. J. Swiergiel, V. S. Marshall, and J. M. Jones. 1998. Embryonic 
stem cell lines derived from human blastocysts. Science $282: 1145-1147$.

Topper, Y. J., and C. S. Freeman. 1980. Multiple hormone interactions in the developmental biology of the mammary gland. Physiol. Rev. 60:1049-1106.

Tucker, H. A. 1981. Physiological control of mammary growth, lactogenesis, and lactation. J. Dairy Sci. 64:1403-1421.

Turner, J. D., and H. T. Huynh. 1991. Role of tissue remodeling in mammary epithelial cell proliferation and morphogenesis. J. Dairy Sci. 74:2801-2807.

Wagner, K. U., C. A. Boulanger, M. D. Henry, M. Sgagias, L. Hennighausen, and G. H. Smith. 2002. An adjunct mammary epithelial cell population in parous females: its role in functional adaptation and tissue renewal. Development 129:1377-1386.
Warner, A. 1992. Gap junctions in development-a perspective. Semin. Cell Biol. 3:81-91.

Weissman, L. 2000. Stem cells: Units of development, units of regeneration, and units in evolution. Cell 100:157-168.

Weissman, I. L., D. J. Anderson, and F. Gage. 2001. Stem and progenitor cells: Origins, phenotypes, lineage commitments, and transdifferentiations. Annu. Rev. Cell Dev. Biol. 17:387-403.

Wheelock, M. J., and K. R. Johnson. 2003. Cadherins as modulators of cellular phenotype. Annu. Rev. Cell. Dev. Biol. 19:207-235.

Zoubiane, G. S., A. Valentijn, E. T. Lowe, N. Akhtar, S. Bagley, A. P. Gilmore, and C. H. Streuli. 2004. A role for the cytoskeleton in prolactin-dependent mammary epithelial cell differentiation. J. Cell Sci. 117:271-280. 